\title{
PENGARUH PROJECT BASED LEARNING - STEM (SCIENCE, TECHNOLOGY, ENGINEERING, AND MATHEMATICS) TERHADAP PEMBELAJARAN SAINS PADA ABAD 21
}

\author{
Yuhana Elva \\ Program Studi Tadris Kimia, UIN Antasari Banjarmasin \\ yuhana.elva02@gmail.com \\ Ratna Kartika Irawati \\ Program Studi Tadris Kimia, UIN Antasari Banjarmasin \\ ratnakartika@uin-antasari.ac.id
}

\begin{abstract}
Abstrak
Tujuan penulisan artikel ini ialah untuk mendiskripsikan pengaruh dari implementasi model Project Based Learning - STEM terhadap pembelajaran sains pada abad 21. Penelitian ini menggunakan metode kualitatif bersifat studi literatur atau telaah pustaka. Berdasarkan data data yang diperoleh dan dianalisis dari beberapa literatur, pembelajaran dengan Project Based Learning - STEM menjadi salah satu alternatif untuk melatih keterampilan siswa pada abad 21. Hasil penelitian menyimpulkan bahwa pengaruh dari implementasi model Project Based Learning - STEM terhadap pembelajaran sains dapat meningkatkan penguasaan konsep dan keterampilan berpikir kritis siswa, kreativitas siswa, kemampuan berkomunikasi, dan keterampilan kolaborasi sehingga dapat mendorong siswa agar memiliki keterampilan pada abad ke-21.
\end{abstract}

Kata kunci: Project Based Learning, STEM, dan Keterampilan Abad 21

\begin{abstract}
The purpose of writing this article is to describe the effect of the implementation of the Project Based Learning - STEM model on science learning in the 21st century. This study uses qualitative methods in the form of literature study or literature review. Based on the data obtained and analyzed from several literatures, learning with Project Based Learning - STEM is an alternative for training student skills in the 21st century. The results of the study conclude that the effect of implementing the Project Based Learning - STEM model on science learning can increase mastery. students' critical thinking concepts and skills, student creativity, communication skills, and collaboration skills so as to encourage students to have skills in the 21 st century.
\end{abstract}

Keywords: Project Based Learning, STEM, and 21st Century Skills

\section{PENDAHULUAN}

Pendidikan diharapkan bisa menanamkan 4 kompetensi yang wajib dimiliki peserta didik pada abad 21, 4 kompetensi itu biasanya disebut dengan $4 \mathrm{C}$ yang terdiri dari (1) Critical Thinking And Problem Solving (berpikir kritis dan menuntaskan masalah), (2) Creativity (kreativitas), (3) Communication Skills (keahlian berkomunikasi), serta (4) Ability to Work Collaboratively (keahlian untuk bekerja sama). (Kemendikbud, 2017). Salah satu upaya yang dapat dicoba untuk meningkatkan aktivitas keterampilan kerja ilmiah yang optimal ialah dengan mempraktikkan model pembelajaran Project Based Learning - STEM. Model ini menekankan pada pendidikan yang berbasis proyek dengan diintegrasikan pada konsep di bidang science, technology, engineering, dan mathematics. (Rustaman, 2016).

Project Based Learning muncul di tahun 1970-an yang berasalnya dari Denmark lebih tepatnya di Universitas Aalborg dan Roskilde, dalam bidang teknik. Bukan cuma semata - mata metode pembelajaran yang membahas tentang teknik, namun Project Based Learning ialah kurikulum yang didesain agar bisa memicu timbulnya berbagai persoalan mendasar mengenai hakekat higher education. Teori mendasar dari perkembangan Project Based Learning, yaitu Carl Rogers tentang teori belajar humanistik, Lewin tentang 
pembelajaran dalam kelompok, John Dewey tentang berartinya pembelajaran yang berasal dari pengalaman, Jerome Bruner tentang belajar selaku proses aktif dimana siswa dapat mentransformasikan data sehingga memunculkan motivasi, retensi, dan pengembangan individu. (Morgan, 1983; Anreasen \& Nielsen, J. L. , 2013; Harmer, 2014).

Project Based Learning mempunyai kemampuan untuk tingkatkan keahlian berpikir siswa tingkatan tinggi dalam melakukan analisis, sintesis, dan penilaian (evaluasi). (Haigt, Kelly, R., \& Bogda, B, 2005). Penerapan Project Based Learning dalam pembelajaran sains bisa meningkatkan hasil belajar siswa pada kemampuan kognitif. (Baran \& Maskan, 2010). Penggunaan model Project Based Learning ini bertujuan untuk mengarahkan siswa agar bisa menyelesaikan permasalahan dan menekankan pembelajaran konstektual dengan cara yang kompleks, seperti memberikan kebebasan dalam mengeksplorasi dan merencanakan kegiatan pembelajaran kolaboratif sehingga dapat melaksanakan proyek akhir untuk menghasilkan produk baru. (Jauhariyyah, F. R, Hadi Suwono, And Ibrohim, 2017).

Pada tahun 1990-an, STEM pertama kali diperkenalkan oleh National Science Foundation Amerika Serikat (AS) yang merupakan gabungan dari empat bidang yaitu science, technology, engineering, dan mathematics. (Hanover Research, 2011). Pendekatan STEM merupakan perpaduan antara sains, teknologi, teknik, dan matematika yang mulai dikembangkan di negara maju dan berkembang. (ElDeghaidy, H, Nasser M, Mohammad A, And Khalid A, 2017). STEM merupakan pembelajaran dengan menggunakan pendekatan konsep - konsep antara science, technology, engineering, dan mathematics sehingga siswa dituntut agar dapat mengaplikasikan konsep STEM yang berkaitan dengan masalah yang ada dalam kehidupan sehari - hari. (Stansell et al., 2016).

Pembelajaran science, technology, engineering, dan mathematics (STEM) bisa digunakan untuk tingkatkan keahlian siswa dalam proses sains sehingga siswa bisa meningkatkan proses berpikir ilmiah untuk pemecahan suatu permasalahan. (Scott, 2012). Pada penelitian Lestari (2018), LKS berbasis STEM dapat meningkatkan kemampuan berpikir kritis siswa. Dan pada penelitian yang dilakukan oleh Siswanto (2018), pembelajaran fisika dengan pendekatan STEM dapat meningkatkan kreativitas mahasiswa.

Pembelajaran dengan menggunakan pendekatan STEM dapat diintegrasikan dengan berbagai model pembelajaran, salah satunya adalah Project Based Learning (Tsai, Huei-Yin, Chih-Chao Chung, And Shi-Jer Lou, 2018). Project Based Learning (PjBL) adalah metode pembelajaran yang direkomendasikan untuk mewujudkan kurikulum 2013, sedangkan STEM merupakan sebuah strategi besar. Oleh karena itu, pengintegrasian Project Based Learning - STEM ini menekankan pada proses desain. Pendekatan sistematis untuk mengembangkan solusi dari permasalahan dengan hasil yang jelas merupakan istilah dalam proses desain. (Capraro, et al, 2013).

Project Based Learning dan STEM mempunyai keunggulan, yaitu model pembelajaran Project Based Learning membuat siswa dapat meguasai konsep dengan menciptakan produk baru, sedangkan dengan pendekatan STEM siswa mampu melakukan proses perancangan dan perancangan ulang (engineering design process) sehingga dapat menciptakan produk terbaik. Integrasi aspek-aspek tersebut dapat berdampak positif pada proses belajar mengajar di sekolah dalam hal peningkatan hasil belajar siswa pada bidang sains dan teknologi. Selain dapat memberikan dampak positif dalam pembelajaran, intergrasi antara Project Based Learning dan STEM merupakan wadah atau sarana untuk mengikuti perkembangan zaman di era globalisasi dengan membangun keterampilan siswa pada abad 21. Pengintegrasian ini mempersiapkan siswa agar dapat mengembangkan keterampilan yang diperlukan untuk bersaing di abad 21 . (Becker \& Park, 2011).

Artikel ini bertujuan untuk mengetahui pengaruh dari implementasi metode Project Based Learning dengan pendekatan STEM 
terhadap pembelajaran sains guna mempersiapkan keterampilan siswa pada abad 21.

\section{METODE PENELITIAN}

Metode penelitian yang digunakan pada artikel ini ialah metode kualitatif. Metode kualitatif adalah studi kritis terhadap pembahasan suatu topik yang bersifat telaah pustaka dalam berbagai sumber yang diananilis secara deskriptif. Sumber utama berupa jurnal atau artikel ilmiah. Langkah langkah penulisan artikel adalah sebagai berikut : 1) Mengumpulkan data tentang Project Based Learning - STEM dan pengaruh dari implementasinya dalam pembelajaran sains, 2) Menganalisis data yang diperoleh.

\section{HASIL DAN PEMBAHASAN}

Project Based Learning ialah model pembelajaran yang berkaitan dengan proyek, sehingga siswa dituntut agar dapat memahami konsep, mengembangkan keterampilan dan kemampuan yang dimiliki, meningkatkan kerja sama atau kolaborasi sehingga dapat menciptakan inovasi baru. Dan STEM ialah pendekatan untuk mempelajari konsep science, technology, engineering, dan mathematics, sehingga dapat meningkatkan proses berpikir siswa dan dapat memecahkan suatu masalah. Adanya integrasi Project Based Learning STEM akan dapat melatih keterampilan siswa di abad 21.

Proses pembelajaran integrasi Project Based Learning - STEM yang efektif meliputi beberapa tahap antara lain sebagai berikut : Tahap 1 (Reflection), tahap ini bertujuan untuk mengarahkan siswa ke dalam konteks permasalahan dan memberikan inspirasi bagi mereka agar bisa menyelidiki dan melakukan investigasi. Tahap 2 (Research), tahap ini bertujuan untuk membentuk riset siswa, guru memberikan pembelajaran sains, dan memilih bahan bacaan, serta metode lainnya guna mengumpulkan sumber data yang relevan sehingga dapat meningkatkan pemahaman konseptual yang bersumber pada proyek. Tahap 3 (Discovery), tahap ini biasanya mengaitkan proses yang menghubungkan penelitian dan data yang diketahui untuk persiapan proyek sehingga dapat melatih siswa menemukan proses pembelajaran dan memastikan apa yang masih belum diketahui. Tahap 4 (Application), tahap ini bertujuan untuk menguji produk atau pemecahan yang sudah dibuat lalu hasil yang didapat digunakan untuk membetulkan langkah sebelumnya sehingga dapat melatih siswa dalam memecahkan masalah. Tahap 5 (Communication), tahap akhir dalam setiap proyek adalah mempresentasikan produk/solusi yang didapat. Communication bertujuan untuk meningkatkan keterampilan berkomunikasi dan berkolaborasi serta menerima dan mempraktikan umpan balik antar teman ataupun lingkup kelas. (LaboyRush, 2010).

Dari langkah - langkah tersebut bisa dikaitkan dengan keterampilan abad 21 . Keterampilan di abad 21 biasa disebut 4C yang meliputi, communication, collaboration, critical thinking and problem solving, serta creativity and innovation. Critical Thinking and Problem Solving ialah kemampuan siswa untuk berpikir pada tingkatan tinggi yang artinya bukan cuma menghafal materi namun juga menggunakan dan memanipulasi materi yang sudah diajarkan sesuai keadaan. Communication ialah interaksi yang digunakan antar individu maupun kelompok untuk saling bertukar pikiran dan gagasan. Collaboration ialah wujud kerjasama dalam kelompok yang dilakukan guna mencapai tujuan bersama. Creativity and Innovation ialah kemampuan siswa dalam menciptakan dan menghasilkan suatu produk baru berbentuk karya. (Winda Marlina, D. J, 2019).

Proses pembelajaran Project Based Learning - STEM pada tahap 1 (reflection), tahap 2 (research), dan tahap 4 (application) bisa meningkatkan penguasaan konsep siswa, didukung dengan penelitian yang dilakukan oleh Afifah, A.N., dkk (2019) didapatkan hasil penelitian bahwa model Project Based Learning - STEM dapat meningkatkan penguasaan konsep siswa dengan kategori sedang dan dapat meningkatkan keterampilan berpikir kritis siswa dengan kategori tinggi. Penelitian ini mengunakan metode Pre - Eksperimental 
dengan desain One - Group Pretest Postest dan sampel dipilih 36 orang siswa dari kelas X MIPA Madrasah Aliyah Negeri di Kabupaten Ciamis tahun pelajaran 2018/2019.

Pada tahap 3 adalah discovery (penemuan) bisa meningkatkan keterampilan berpikir kreatif, didukung dengan penelitian yang dilakukan oleh Kornelia Devi Kristiani, dkk (2017) didapatkan hasil penelitian bahwa skor $n$ gain menunjukkan 0,783 yang artinya peningkatan keterampilan berpikir kreatif peserta didik mencapai kategori tinggi. Penelitian ini menggunakan metode penelitian Pre - Eksperimental Design dengan desain penelitian One - Group Pretest - Postest Design dan sampel yang dipilih yaitu 32 siswa dari kelas VIII A SMP Negeri 5 Madiun tahun pelajaran 2016/2017.

Pada tahap 5 (communication) bisa meningkatkan kemampuan berkomunikasi, didukung dengan penelitian yang dilakukan oleh Muhammad Nur Chalim, dkk (2019) diperoleh hasil bahwa kemampuan komunikasi matematis yang diperoleh dengan model pembelajaran PjBL - STEM mencapai ketuntasan belajar klasikal. Penelitian ini menggunakan mixed methods dengan explanatory sequential design dengan teknik cluster random sampling. Sampel yang dipilih yaitu siswa kelas XI SMK Negeri 7 Semarang tahun ajaran 2017/2018.

Selain itu, pada penelitian yang dilakukan oleh Dwita Triana, dkk (2020) yang dilakukan di SMA Negeri 4 Medan dan SMA Negeri 16 Medan kelas X. Penelitian menggunakan metode purposive sampling dengan desain one group pretest posttest. Diperoleh hasil penelitian bahwa

\section{DAFTAR PUSTAKA}

Afifah, A.N., Ilmiyati, N., \& Toto. 2019. Model Project Based Learning (PjBL) Berbasis Stem Untuk Meningkatkan Penguasaan Konsep Dan Keterampilan Berpikir Kritis Siswa. Quagga: Jurnal Pendidikan dan Biologi, 11(2), 73-78. doi: 10.25134/quagga.v11i2.1910.

Anreasen, L. B., \& Nielsen, J. L. 2013. Dimensions of problem based learning pelaksanaan kegiatan pembelajaran berdasarkan aktivitas guru didapatkan skor 0,915 dengan kategori sangat baik. Selanjutnya, keterampilan berpikir kritis dan pemecahan masalah mendapatkan skor ratarata $\mathrm{N}$-Gain 0,587 dengan kategori sedang, kreativitas dan keterampilan inovatif mendapatkan skor rata-rata 0,809 , skor keterampilan kolaborasi 0,816 dan skor keterampilan komunikasi 0,825 dengan semua kategori sangat baik.

Dari beberapa penelitian di atas dapat diketahui bahwa dalam proses pembelajaran sains dari model pembelajaran Project Based Learning - STEM dapat melatih siswa agar memiliki keterampilan $4 \mathrm{C}$.

\section{SIMPULAN}

Berdasarkan hasil dan pembahasan dapat disimpulkan bahwa model pembelajaran Project Based Learning STEM memiliki pengaruh yang positif terhadap hasil belajar siswa. Adapun pengaruh dari implementasi model Project Based Learning - STEM yaitu : (1) Adanya peningkatan penguasaan konsep dan keterampilan berpikir kritis siswa; (2) Peningkatan keterampilan berpikir kreatif siswa; (3) Meningkatkan kemampuan berkomunikasi siswa; (4) Meningkatkan aktivitas guru, keterampilan berpikir kritis dan pemecahan masalah, kreativitas dan keterampilan inovatif, keterampilan kolaborasi, serta keterampilan komunikasi pada siswa.

Dengan demikian model Project Based Learning - STEM dalam pembelajaran sains dapat mendorong siswa untuk memiliki keterampilan abad 21.

- dialogue and online collaboration in projects. Journal of problem Based Learning in Higer Education, 1 (1), 210-229.

Baran, M. \& Maskan, A. 2010. The Effect of Project-Based Learning on Pre-Service Physics Teachers' Electrostatic Achievements. Cypriot Journal of Educational Sciences, 5, 243-257.

Becker, K. H., \& Park, K. 2011. Integrative Approaches among Science, 
Technology, Engineering, and Mathematics (STEM) Subjects on Students Learning. A Meta-Analysis Journal of STEM Education.

Capraro, Robert M., Mary Margaret Capraro, And James R. Morgan. 2013. Stem Project Based Learning: An Integrated Science, Technology, Engineering, And Mathematics (Stem) Approach. Rotterdam: Sense Publisher.

Dwita Triana, Y. U. 9 (2) 2020. Effectiveness of Environmental Change Learning Tools Based on STEM-PjBL Towards 4C Skills of Students. Journal of Innovative Science Education, 181 - 187.

El-Deghaidy, Heba, Nasser Mansour, Mohammad Alzaghibi, And Khalid Alhammad. 2017. Context Of Stem Integration In Schools : Views From InService Science Teachers. Eurasia Journal Of Mathematics Science And Technology Education, 13, 2459-84.

Haigt, W., Kelly, R. , \& Bogda, B. 2005. Project-based learning: a natural fit with discance education. Online classroom, Academic Search Complete database.

Hanover Research. 2011. K-12 STEM education overview.

Harmer, N. 2014. Project-based learning. Plymouth, England: PlymouthUniverstiy.

Jauhariyyah, Farah Robi'atul, Hadi Suwono, And Ibrohim. 2017. Science, Technology , Engineering And Mathematics Project Based Learning ( Stem-Pjbl ) Pada Pembelajaran Sains. In Pros. Seminar Pend. Ipa Pascasarjana Um, II, 432-36.

Kemendikbud. 2017. Pendidikan Karakter Dorong Tumbuhnya Kompetensi Siswa Abad 21. Retrieved from https://www.kemdikbud.go.id/main/bl og/2017/06/pendidikan-karakterdorong-tumbuhnya-kompetensi-siswaabad-21.

Kornelia Devi Kristiani, T. M. 15 Agustus 2017. Pengaruh Pembelajaran STEMPjBL Terhadap Keterampilan Berpikir Kreatif. Prosiding SNPF (Seminar Nasional Pendidikan Fisika), 266-74.
Laboy-Rush, D. 2010. Integrated STEM Education through Project-Based Learning. www.learning.com/stem/whitepaper/in tegrated-STEM-through-Projectbased-Learning.

Lestari, D. A. B, Astuti, B., \& Darsono, T. 2018. Implementasi LKS Dengan Pendekatan STEM (Science, Technology, Engineering, and Mathematics) untuk Meningkatkan Kemampuan Berpikir Kritis Siswa. Jurnal Pendidikan Fisika dan Teknologi, Volume 4 No.2.

Morgan, A. 1983. Theoretical aspects of project-based learning in higher education. British Journal of Educational Technology, 14 (1), 66-78.

Nur Chalim, M., Mariani, Scholastika, \& Wijayanti, Kristina. 2019. Kemampuan Komunikasi Matematis Siswa SMK Ditinjau dari Self Efficacy pada Setting Pembelajaran Project Based Learning Terintegrasi STEM. PRISMA, Prosiding Seminar Nasional Matematika, Vol 2, 540-550.

Rustaman, N. Y. 2016. Pembelajaran Sains Masa Depan Berbasis STEM Education. Prosiding Seminar Nasional Bio-Edu 1 STKIP PGRI Sumatra Barat, 1-17.

Scott, C . 2012. An Investigation of Science, Technology, Engineering and Mathematics (STEM) Focused High School in The U.S. Journal of STEM Education, 30-39.

Siswanto, Joko. 2018. Keefektifan Pembelajaran Fisika dengan Pendekatan STEM untuk Meningkatkan Kreativitas Mahasiswa. Jurnal Penelitian Pembelajaran Fisika, Vol. 9 No. 2.

Stansell, A., Tyler-Wood, T., \& Stansell, C. 2016. Inventing The Invented for STEM Understanding. Makalah disajikan dalam The 13th International Conference on Cognition and Exploratory Learning in Digital Age (CELDA 2016).

Tsai, Huei-Yin, Chih-Chao Chung, And ShiJer Lou. 2018. Construction And Development Of Istem Learning Model. Eurasia Journal Of 
Mathematics, Science And Technology Education, 14, 15-32.

Winda Marlina, d. D. 2019. 4C Dalam Pembelajaran Matematika Untuk
Menghadapi Era Revolusi IndustriI 4.0.

Prosiding Sendika, Vol 5, No 1. 